\title{
REVISITANDO O CLÁSSICO MOBY DICK: O SIGNIFICADO AMBIENTAL DA OBRA À LUZ DO DIREITO INTERNACIONAL AMBIENTAL SOBRE A PRESERVAÇÃO DA VIDA MARINHA BALEEIRA
}

\author{
REVISITING THE CLASSIC MOBY DICK: THE ENVIRONMENTAL \\ SIGNIFICANCE OF THE NARRATIVE IN THE LIGHT OF INTERNATIONAL \\ ENVIRONMENTAL LAW ON THE PRESERVATION OF THE WHALING MARINE \\ LIFE
}

${ }^{1}$ Ana Cristina Alves de Paula

\section{RESUMO}

O presente artigo visa analisar o significado ambiental da obra Moby Dick, narrativa que, em meados do século XIX, alertou, ainda que de modo indireto, quanto à necessidade de preservação da natureza face aos excessos da atividade baleeira. Para tanto, analisaram-se as principais normativas que compõem o regime ambiental de proteção à vida marinha baleeira, uma das quais permitiu exceções à proibição da caça, baseada tanto em supostas necessidades de pesquisa científica quanto na reivindicação de práticas culturais, e a decisão da CIJ no caso apresentado pela Austrália em face do Japão.

Palavras-chave: Moby Dick; Direito Internacional Ambiental; Convenção Internacional para a Regulamentação da Pesca da Baleia; Comissão Baleeira Internacional; Caso Austrália vs. Japão.

\begin{abstract}
This article aims to analyze the environmental significance of Moby Dick, narrative that, in the mid-nineteenth century, warned, indirectly, on the need to preserve nature against the excesses of whaling. For this, we analyzed the main regulations that composes the environmental protection regime for whaling marine life, one of which allowed exceptions to the prohibition of hunting, based both on alleged scientific research needs as the claim of cultural practices, and the decision of the ICJ in the case brought by Australia in face of Japan.
\end{abstract}

Keywords: Moby Dick; International Environmental Law; International Convention for the Regulation of Whaling; International Whaling Commission; Case Australia vs. Japan.

\footnotetext{
${ }^{1}$ Mestranda em Direito pelo Programa de Pós-Graduação em Direito da Universidade Estadual Paulista "Júlio de Mesquita Filho" - UNESP, São Paulo (Brasil). E-mail: a.cris.direito@ gmail.com
} 


\section{INTRODUÇÃO}

Sou atormentado por uma coceira interminável por coisas distantes. Eu adoro navegar por mares proibidos - Herman Melville.

As preocupações com o meio ambiente se fazem presentes na maior parte dos ordenamentos jurídicos internos e nas normas consagradas no seio do Direito Internacional do Meio Ambiente em decorrência da conscientização dos problemas advindos da degradação ambiental generalizada e da crescente extinção de espécies animais e vegetais no planeta.

No marco da proteção às baleias, a cooperação interestatal é especialmente importante, vez que busca tutelar animais migratórios que habitam as águas jurisdicionais de Estados costeiros, assim como o alto mar. Os marcos regulatórios principais que incentivam a cooperação são constituídos pela Convenção Internacional para a Regulamentação da Pesca da Baleia, complementados pela Convenção sobre a Pesca e Conservação dos Recursos Vivos de Alto-Mar e pela Convenção das Nações Unidas sobre o Direito do Mar.

O presente artigo visa analisar, sob a perspectiva ambiental, a obra Moby Dick, de Herman Melville. O livro é escrito em formato de diário do personagem Ishmael, alternandose entre sua história a bordo do navio Pequod e a fixação doentia do Capitão Ahab em cruzar os mares a fim de se vingar da baleia Moby Dick e trechos de não ficção sobre o mercado dos produtos de baleia do século XIX. O final do livro é previsível, mas mesmo assim permanece a discussão ambiental sobre os impactos nocivos da atividade baleeira. Assim sendo, há todo o interesse em revisitar o mencionado texto, haja vista ter teorizado, de uma forma literária, mas simples, muitos dos aspetos presentes no discurso da ecocrítica atual.

O desenvolvimento da discussão neste artigo se faz em três seções, começando por uma breve exposição da biografia do autor e da estruturação do romance, prosseguida por uma explanação sobre a atividade baleeira com um enfoque histórico a partir do século XIX, destacando o gradual processo de proibição da caça e alguns questionamentos sobre o futuro da prática. A seguir, serão expostas as principais características do regime de proteção internacional das baleias, o que permitirá obter uma visão geral do contexto no qual foi constituído, sua estrutura institucional e seus mecanismos de controle. Posteriormente, serão comentados os principais desafios e perspectivas do regime mencionado, o que permitirá concluir o estudo com as expectativas a respeito do assunto.

Por fim, será analisado o caso da Corte Internacional de Justiça ‘Austrália vs. Japão’, apresentado pela Austrália em maio de 2010 sob a alegação de que o Japão violou na Antártica 
obrigações assumidas na Convenção Internacional para a Regulamentação da Pesca da Baleia (ICRW), assim como outras obrigações internacionais para a preservação de mamíferos marinhos e da vida marinha (CIJ, 2010).

Pretendeu-se, de modo geral, apresentar uma nova abordagem de interpretação do Direito Ambiental, tendo por fundamento a compreensão da literatura como uma importante ferramenta pedagógica. Optou-se pela pesquisa bibliográfica de diversos autores que pudessem, de alguma forma, colaborar com o amadurecimento do raciocínio jurídico aqui apresentado.

\section{HERMAN MELVILLE: DA REALIDADE PARA A FICÇÃO}

Antes de iniciar a análise proposta, é importante discorrer um pouco sobre a trajetória do autor da obra Moby Dick, uma vez que sua biografia certamente tem alguma influência na forma como a história da grande baleia branca é contada.

Herman Melville nasceu em Nova York, no dia $1^{\circ}$ de agosto de 1819, em uma família de origens inglesa e holandesa. Durante sua infância, a situação social da família era confortável. Mas seu pai, um senhor refinado, teve sérios problemas financeiros que o levaram à falência no ano de 1830. Ele morreu logo em seguida, deixando a mulher e os oito filhos numa situação instável, fazendo com que a educação de Herman cessasse por volta dos seus quinze anos de idade. Ele começou a trabalhar para auxiliar no sustento da família, e foram várias as suas ocupações: bancário, vendedor na loja de peles do irmão, professor e colono.

Foi com o pseudônimo de L.A.V. que Herman Melville publicou, em 1839 uma composição intitulada Fragmentos Literários de uma Escrivaninha, trabalho com inclinações românticas e um estilo ainda indefinido. Essa publicação não trouxe a Melville críticas muito positivas. Assim, aos vinte anos e sem muitas perspectivas, no mesmo ano, foi empregado, graças a seu irmão mais velho, como camareiro no navio mercante 'St. Lawrence', no qual embarcou rumo a Liverpool. Anos mais tarde (1849) contaria no livro Redburn a decepcionante experiência dessa viagem em relação aos marujos grosseiros e a exaustão da vida a bordo.

Voltando à sua Nova York natal, conseguiu aulas em um colégio, o qual encerrou as suas atividades algum tempo depois. Diante disso, ele foi tentar a sorte no oeste, mas no final de 1840 retornou a Nova York sem nenhum dinheiro, o que o faz embarcar no navio baleeiro 'Acushnet' pelos mares do sul, em uma viagem com duração de dezoito meses, o que lhe forneceria muito da matéria-prima utilizada posteriormente pelo escritor em sua obra-prima. 
Em julho de 1842, Melville desertou do navio com um amigo no porto de Nukahiva, na Polinésia, vivendo entre os habitantes das ilhas Marquesas por vários meses. Juntou-se à embarcação comercial australiana 'Lucy Ann' em 1841, no qual acabou se unindo a um motim organizado pelos tripulantes insatisfeitos pela falta de pagamento. O resultado foi que Melville foi preso em uma cadeia no Taiti, da qual fugiu pouco tempo depois. As peripécias neste navio e a descrição do modo de vida dos nativos da ilha resultaram no livro Typee (1846), uma reportagem narrativa. E das experiências vividas em Papeete, no Taiti, após desembarcar do 'Lucy Ann', decorreu o livro Omoo, de 1847. Os referidos livros lhe renderam muito sucesso de crítica e público e certo conforto financeiro.

As disputas entre ingleses, franceses e norte americanos sobre o Havaí e o Taiti incentivaram Melville a se alistar na marinha americana, relatando em White Jacket, de 1850, o ambiente disciplinar muito rígido. Voltou aos Estados Unidos em 1844, na fragata chamada 'United States', que aportou em Boston.

Casou-se em 4 de agosto de 1847 com Elizabeth Shaw e, em 1850, mudou-se com a esposa para Arrowhead, uma fazenda em Pittsfield (atualmente um museu), no estado norteamericano de Massachusetts, onde redigiria Moby Dick, considerado por inúmeros estudiosos como um dos romances mais importantes da literatura ocidental. Melville e sua esposa viveram nessa fazenda por quinze anos. Durante esse tempo, o casal tornou-se íntimo do vizinho e colega de letras, o escritor Nathaniel Hawthorne (1804-1864).

Em uma fase de definição da identidade estado-unidense, quando a estética romântica dominava o Novo Mundo, a ética da literatura deles fez eco ao bardo Walt Whitman (18191892) e sua busca quase religiosa pela essência das coisas e dos homens. Estudiosos da literatura norte-americana viriam a chamar Hawthorne, Whitman e Melville, assim como outros escritores da Nova Inglaterra de então, de "transcendentalistas" por conta do viés religioso, por vezes messiânico, da sua literatura, que buscava, através das letras, uma conexão de bondade, compaixão, sentimento de amor onipresente e virtude com todo o Universo.

Em 1851 foi publicado Moby Dick. Acontece que este foi um daqueles casos no qual o autor só tem seu talento reconhecido postumamente: o livro só teve cerca de 3 mil cópias vendidas enquanto Melville estava vivo. Na medida em que o escritor optou por tratar de temas mais complexos e elaborados, sua obra foi tornando-se desinteressante para os leitores que esperavam simples relatos de aventuras, como seus primeiros escritos.

Nas histórias do período que vai de 1853 a 1856, nota-se uma forte preocupação autobiográfica. O duro esquecimento por parte do público e o desgoverno da carreira literária 
de Melville refletiram-se no papel em situações de retiro pessoal, resignação, derrota, resistência estoica e sofrimento passivo - além de personagens vivendo e sobrevivendo após terríveis desastres - e esforços, por vezes vãos, para evitar catástrofes maiores.

No período de 1856 a 1885, Melville abandonou a escrita em prosa (assim como abandonara a ideia de uma carreira bem-sucedida de escritor), dedicando-se apenas a versos. Em 1860, o período criativo de Melville já terminara, e ele tentou ganhar dinheiro como palestrante. Mudou-se para a cidade de Nova York durante a Guerra Civil Norte-Americana e três anos depois, em 1866, foi nomeado fiscal da alfândega. Permaneceu no cargo burocrático por dezenove anos. Ele faleceu em 28 de setembro de 1891, aos 72 anos, em Nova York, em total obscuridade. A título de curiosidade, o obituário do jornal 'The New York Times' registrava o nome de "Henry Melville".

Somente a partir das primeiras décadas do século XX é que a obra de Melville seria reavaliada em uma escala de importância, renovando o prestígio do autor. De acordo com William Carlos Dantas dos Santos, como toda a sua literatura é perpassada pela busca da perfeição do homem e pela constante luta entre o Bem e o Mal, a crítica da segunda metade do século XX viu em Melville um precursor do existencialismo, e o escritor francês Albert Camus chamou-o de "O Homero do oceano Pacífico". Antes ou depois de Melville, nunca a ideia de retidão moral foi tão atraente, justificada e ou transcendente (SANTOS, 2011, p. 9).

\subsection{O romance Moby Dick e sua estrutura}

Com toda certeza, Moby Dick é um clássico da literatura mundial. Não é sem razão que, tendo sido publicado em 1851, tenha sido traduzido para inúmeras línguas, adaptado para versões em quadrinhos e versões condensadas para crianças, e, pelo menos duas vezes, para o cinema (1956, sob a direção de John Huston, com Gregory Peck no papel de Ahab, e em 1998, sob a direção de Franc Roddam, com Patrick Stewart, no referido papel).

Ademais, a obra prima de Melville foi baseada na história do Capitão George Pollard e de seu navio baleeiro 'Essex' que, em 1823, foi atingido por uma baleia antes de naufragar. Essa história real, cujos sórdidos detalhes são capazes de fazer gelar a alma do mais corajoso dos homens, é relatada em detalhes no arrepiante No Coração do Mar, de Nathaniel Philbrick, que contrapõe a bravura do ser humano diante de uma situação extraordinária à sua impotência em face de uma força da natureza amplamente superior à sua. 
Moby Dick não é um simples romance de aventuras. De fato, é difícil classificar que tipo de obra é. Não se trata de um simples romance de viagem, nem de um drama, nem um romance psicológico, mas de uma combinação, ao mesmo tempo, de todos esses elementos e vários outros. É uma obra realista que descreve em detalhes a dura vida do homem do mar, as embarcações, os métodos de caça e beneficiamento dos produtos extraídos e as relações que os embrutecidos marujos travavam entre si. $^{2}$ É o registro do comportamento de uma época de valores tão distantes dos atuais, mas é também algo que vai além disso tudo. Os símbolos e metáforas do texto contrastam com sua linguagem estilizada, o que envolve o leitor numa espiral que ora ascende, ora decai, tal qual à obsessão do próprio Capitão Ahab.

O livro narra, por intermédio de Ishmael (o narrador testemunha de Melville), como um grupo de caçadores de baleias, por volta de 1800 em New Bedford, Connecticut (costa nordeste dos Estados Unidos), embarcou no Pequod, um dos muitos navios baleeiros da época. O comércio de caça à baleia era responsável por boa parte da economia dos Estados Unidos no período retratado no romance. Vários arpoadores, provenientes dos mais diversos pontos do globo, foram contratados para o que, conforme pensaram, seria apenas mais uma viagem de caça, com único objetivo de capturar baleias.

Entretanto, em breve os arpoadores tomam conhecimento de que o objetivo de Ahab, o sinistro e misterioso Capitão do Pequod, não é uma viagem em busca de lucro, mas de vingança: Ahab quer localizar e destruir uma gigantesca baleia cachalote branca, denominada Moby Dick (apresentada como um ser misterioso, silencioso e poderoso, que reina absoluto nos mares, que não se pode compreender - e muito menos dominar), que algum tempo antes o mutilara, arrancando uma de suas pernas. Contra todo e qualquer bom senso, o Capitão Ahab levará adiante seu irreprimível desejo de vingança, que culminará em desgraça.

Segundo Heitor Ferraz, o livro não segue uma narrativa linear:

\begin{abstract}
Sua narrativa exuberante e de fôlego desliza sobre a superfície de vários modos de escrita: o do relato de viajante, puro e simples; passando pela crônica de costumes, quando ele descreve deliciosamente uma cidade como New Bedford ou Nantucket, ou apenas a vida em uma pousada; o do texto científico, com a sua classificação dos tipos de baleia; do filosófico, quando entra na alma humana para tentar perceber o que há de estranho no homem, de incongruente ou irracional; ou mesmo do lírico, quando a voz retorna para o coração de Ishmael, o protagonista desse grande livro. (FERRAZ, 2010, p. 428).
\end{abstract}

\footnotetext{
${ }^{2}$ De acordo com Otto Maria Carpeaux, Moby Dick pode até ser considerado um manual de pesca a baleia. E com razão. As minúcias descritivas de Melville abrangem cada procedimento envolvido na pesca, desde o rastreamento até a movimentação, da alimentação do animal até seus hábitos de reprodução, suas classificações taxonômicas e estudos detalhados sobre seu organismo.
} 
Melville termina a narrativa de Moby Dick de modo arrebatador. No confronto final, o Pequod é destruído e todos são mortos, com exceção de Ishmael, que se salva agarrado ao caixão que Queequeg mandara fazer para si, mas jamais utilizou. É curioso que o único sobrevivente tenha escapado por ter se agarrado a um caixão.

A densa narrativa de Melville apresenta enredo muito rico em verossimilhança, com impressionante equilíbrio entre bases históricas e a fantasia propriamente do autor. A obra, entretanto, tem suas falhas. Como qualquer outro livro, ela é um retrato de sua época, bem como da visão de mundo de seu autor. Desta forma, verificam-se conceitos ultrapassados, como o de baleias sendo consideradas peixes, e exemplos claros e revoltantes (para leitores modernos) de misoginia e racismo.

Até a segunda metade do século XX, a preocupação ambiental ocorria na forma de ações de preservação em resposta a problemas pontuais, de impacto imediato, ou com a intenção de preservar recursos naturais tidos como finitos. Tais ações ocorriam de forma localizada e não havia a noção de que agressões feitas ao meio ambiente, mesmo que circunscritas a apenas uma região, poderiam afetar todo o país, ou até mesmo aos países vizinhos.

É possível dizer que o "ponto da virada" no que diz respeito à percepção dos seres humanos (e dos países) quanto à preservação ambiental se deu quando a soma de suas ações predatórias ameaçou o estoque de um bem comum a todos os países: as baleias (DUARTE, 2016).

Séculos de caça indiscriminada levaram a uma redução drástica na população destes cetáceos nos oceanos. Como a caça é feita em oceano aberto, e sendo o bem comum a todos os países, ações locais de preservação não teriam resultado - foi preciso que a discussão e o compromisso fossem realizados por todos os interessados na indústria, ao redor do globo (DUARTE, 2016).

A obra Moby Dick pode ser encarada como uma homenagem do autor à força desses animais incríveis que são as baleias. As descrições de caça e abate dos cachalotes ao longo do livro são cruelmente terríveis, mas servem como o registro de um passado que não pode ser esquecido para não ser repetido. Além disso, o amargo Capitão Ahab deve ser visto como um homem fascinado e ao mesmo tempo com um medo tão grande da magnitude da natureza, que sua única forma de reagir é tentando destruir um oponente maior, mais forte e mais nobre. A discussão ambiental do livro, que abarca também o âmbito econômico e político, é a que ganha mais destaque atualmente no embate do desmedido consumo humano e seus impactos no plano ecológico global. 
Hoje em dia, confrontada com as crises ambientais profundas trazidas pela industrialização e pelo desenvolvimento tecnológico, a humanidade deve aprender com Melville e sua obra Moby Dick, e se orientar de forma a mudar de mentalidade e adotar um novo estilo de vida, estabelecendo um relacionamento sustentável com a natureza e, assim, beneficiando toda a biosfera.

Herman Melville foi um homem à frente de seu tempo, já demonstrando uma preocupação mais profunda com a deterioração do meio ambiente. Com efeito, quanto mais se estudar Moby Dick, mais se questionará o direito dos seres humanos sobre a natureza e a cegueira quase total do homem no que tange ao cuidado para com a natureza e o mundo em que vive.

Por fim, evidente é a advertência de Melville de que o homem pode desafiar a natureza e explorar os recursos naturais, mas a natureza sob a forma de a baleia branca responde ao desafio do homem: "[...] Retribuição, vingança rápida, maldade eterna estavam em todo o seu aspecto e, apesar de tudo o que o homem mortal poderia fazer, o contraforte sólido branco da testa feriu estibordo do navio, até que os homens e as madeiras cambalearam"(MELVILLE, 2012, p. 143).

\title{
2 PANORAMA GERAL DA PROTEÇÃO INTERNACIONAL DAS BALEIAS
}

\subsection{O desenvolvimento da atividade baleeira}

\begin{abstract}
Naquele momento, matar a baleia era nosso maior desejo. Parecia que todos os nossos problemas seriam resolvidos com a morte do gigantesco mamífero, que, ao que tudo indicava, era mesmo um monstro assassino, cruel e desalmado.
\end{abstract}

As baleias são mamíferos marinhos de singular importância para o equilíbrio natural dos mares, uma vez que suas fezes são ricas em ferro e promovem o afloramento das algas dos fitoplânctons existentes, que absorvem o dióxido de carbono da atmosfera.

Consoante Juliana Rodrigues Moron,

\begin{abstract}
a Ordem Cetacea se divide nas Subordens Mysticeti e Odontoceti, compreendendo os mamíferos marinhos tratados neste trabalho. Os odontocetos são cetáceos com um único respiradouro (orifício nasal) e que possuem dentes, alimentam-se de peixes e cefalópodes. Todos os botos e golfinhos, e algumas baleias - tais como as "sperm", "pilot" e "killer" - estão inseridos nessa subordem. Já os misticetos são os cetáceos que possuem dois respiradouros e cerdas na boca para retenção do plâncton filtrado pela água, sendo por isso, chamadas de baleias de barbatana (MORON, s/d, p.1).
\end{abstract}

Conforme a Enciclopédia Escolar Britannica, o cachalote é a maior das baleias com dentes, facilmente reconhecido pela sua enorme cabeça quadrada e maxilar inferior estreito. $\mathrm{O}$ cachalote é azul escuro, cinza ou marrom, com manchas brancas na barriga. É robusto e tem 
pequenas barbatanas e uma série de corcundas arredondadas em sua parte traseira. Os machos alcançam um comprimento máximo de cerca de 20 metros e as fêmeas, cerca de 17 metros. O peso destes grandes animais varia entre 38 e 52 toneladas. A cabeça constitui um terço do comprimento total do corpo e, estima-se, mais do que um terço do peso do corpo. A mandíbula inferior é normalmente equipada com 36 a 50 grandes dentes cônicos.

A cabeça apresenta um nariz desenvolvido e um lábio superior onde está localizado o órgão do espermacete; o fluído do espermacete, que tem a textura de uma cera branca, fora extraído para iluminação e lubrificação. O cachalote chega a ter até 2.000 litros dessa substância. O órgão do espermacete pode estender-se até 40 por cento do comprimento da baleia. Os cachalotes, portanto, são comercialmente valiosos e têm sido caçados por vários séculos, encontrando-se na lista dos animais ameaçados de extinção.

A baleação, de acordo com a Comissão Baleeira Internacional, é definida como a caça de baleias para usufruto de sua carne e subprodutos. Esta atividade remonta ao século IX, segundo os primeiros registros de caça em larga escala na área do golfo de Biscaia, próximo às costas espanholas e francesas, sendo que em meados do século XIX muitos outros países já haviam investido nesta indústria, desenvolvendo grandes companhias (MORON, s/d, p.1).

A principal substância extraída era a gordura do animal, convertida em óleo para abastecer os lampiões utilizados na iluminação das cidades, assim como para fabricar argamassa utilizada na construção de igrejas e fortalezas. Por seu lado, as “barbatanas”, ou seja, o aparelho de cerdas da boca que filtra o alimento, eram muito úteis na fabricação de espartilhos. Destaque-se também a valorização do âmbar cinzento (localizado nos intestinos do animal), muito utilizado como fixador de perfumes.

De acordo com Alexandra Leão et al., até metade do século XIX havia pouca tecnologia envolvida no processo de captura de baleias, o que era refletido no fato de que apenas as baleias mais lentas como a cachalote, a franca e a jubarte podiam ser capturadas (HJORT, 1937, apud LEÃO et al., s/d, p. 4). Os barcos para a perseguição eram movidos à vela ou a remo e os arpões eram lançados manualmente. No entanto, a atividade baleeira mudou como um todo com o avanço tecnológico voltado à prática, iniciado em 1860 com a criação de arpões explosivos $^{3}$, que aumentaram a distância mínima entre a baleia sendo caçada e o barco (LEÃO et al., s/d, p. 4).

\footnotetext{
3 Arpão explosivo é um instrumento de pesca de baleias que explode ao ser cravado no corpo do animal, provocando sua morte. Pode ser inserido à mão ou atirado com canhão ou objeto similar.
} 
O uso de velas deu lugar ao vapor, e barcos movidos dessa maneira, em conjunto com o emprego dos arpões explosivos, permitiram a perseguição e a captura de qualquer espécie de baleia (BAKER; CLAPHAM, 2002, apud LEÃO et al., s/d, p. 4). Um problema enfrentado pela indústria baleeira era sua dependência das fábricas terrestres que processavam as baleias caçadas, situação que foi resolvida com a introdução de barcos-fábricas que serviam à mesma função e ainda hoje são utilizados. Essas verdadeiras fábricas flutuantes podem operar em alto mar por meses, o que facilita a caça em mar aberto (BAKER; CLAPHAM, 2002, apud LEÃO et al., s/d, p. 4).

Com o passar do tempo, os métodos evoluíram e as baleias tem sido caçadas de forma devastadora, claramente oposta ao conceito de desenvolvimento sustentável. Diante dos efeitos da exploração não sustentável por parte da indústria e da consequente diminuição de certas espécies negociáveis no comércio nacional e/ou internacional, verificou-se a necessidade de uma tutela internacional.

\subsection{O regime de proteção às baleias}

De acordo com Alexandra Leão et al., considerando-se que a maior parte da população de baleias de espécies de grande porte se encontra em águas internacionais ${ }^{4}$, os esforços multilaterais são indispensáveis à regulação das atividades baleeiras (OBERTHÜR, 1998, apud LEÃO et al., s/d, p. 9). Essa regulação surge a partir de duas motivações na comunidade internacional: a primeira, essencialmente econômica, é evitar a superoferta de produtos provenientes dessas espécies, impedindo assim uma diminuição em seus preços; a segunda, por sua vez, é referente à sustentabilidade, e constitui uma preocupação com a sobrevivência das espécies. Nas últimas décadas, surgiu uma terceira razão para a restrição das atividades baleeiras, que, baseada em considerações éticas, defende a preservação total das baleias, independentemente das espécies estarem ameaçadas ou não, e independentemente de razões econômicas (OBERTHÜR, 1998, apud LEÃO et al., s/d, p. 9).

Em 1925, a "Liga das Nações", organização internacional formada após a Primeira Guerra, reconheceu que as baleias estavam sendo exploradas indiscriminadamente, sendo portanto, necessário controlar as atividades baleeiras. Em 1930, o Bureau of International

\footnotetext{
${ }^{4}$ As Águas Internacionais, ou Alto Mar, incluem todas as áreas marítimas que não estão sob a jurisdição de um Estado, ou seja, todas aquelas que não fazem parte das águas arquipelágicas de um Estado arquipélago ou do mar territorial e da zona econômica exclusiva de um Estado costeiro (VALES, 2011).
} 
Whaling Statistics foi organizado a fim de se manter a par das caças, surgindo em 24 de setembro de 1931 a Convenção para a Regulamentação da pesca a Baleia, primeiro tratado de regulamentação internacional. Posteriormente, em 8 de junho de 1937, foi concluído o Acordo Internacional para a regulamentação da Pesca a Baleia (MORON, s/d, p. 2).

Em 1946, ocorreu em Washington a Conferência Internacional da Baleia, na qual foi estabelecida a Convenção Internacional para a Regulamentação da Pesca da Baleia (ICRW), assinada em 2 de dezembro de 1946 pelos 19 países presentes. Essa convenção entrou em vigor em 1948, objetivando tanto promover um desenvolvimento ordenado da indústria baleeira quanto conservar os recursos provenientes desse animal (OBERTHÜR, 1998, apud LEÃO et $a l .$, s/d, p. 10). Para tanto, seu texto vela pela completa proteção de certas espécies, estabelece limites sobre o número e o tamanho de espécies que podem ser capturadas; fixa a abertura e o fechamento das temporadas de pesca permitidas e as áreas onde ela pode ocorrer, assim como torna obrigatória a abstenção de apresar ou matar baleias lactantes ou baleias fêmeas acompanhadas por filhotes lactantes (PEW WHALES COMMISSION BULLETIN, 2012, apud ÁLVAREZ; ANDRADE, 2012, p. 6). Além disso, a Convenção visa regular os tipos e especificações de mecanismos, aparelhos e instrumentos que podem ser usados, os métodos de medição, os formulários para registro da pesca e outros dados estatísticos e biológicos. A todos os países que assinaram foi garantido o direito de emitir licenças, com justificativa científica, para a atividade baleeira. Ademais, a Convenção permitiu dois tipos de pesca: a realizada para fins de investigação científica e a pesca artesanal realizada por povos aborígenes de regiões onde houver tradição secular e tal atividade for importante para a sobrevivência das sociedades e culturas que lhe estão associadas.

Para conseguir permissão de pesca de subsistência, em conformidade com os limites de cotas, Juliana Rodrigues Moron ensina que existe um estudo das origens, características e desenvolvimento dessa atividade, para chegar a um consenso dos mecanismos apropriados adotados dentro dessa comunidade baleeira, visando assegurar a conservação das baleias (MORON, s/d, p. 7). Quanto à pesca com finalidade científica, nos termos do artigo VIII da Convenção, seria facultada a permissão aos Estados Partes para conceder aos seus nacionais licença ou permissão especial, autorizando-os a matar, capturar e tratar baleias com propósito de pesquisas científicas, sob reserva de tais restrições, quanto ao número e de outras condições que o governo contratante julgar útil prescrever. Destaque-se que a intenção das previsões da ICRW que autorizam tais modalidades de pesca não busca prover carne de baleia com fins comerciais. 
Em 1958, a Convenção sobre a Pesca e Conservação dos Recursos Vivos de Alto-Mar reconheceu a necessidade de cooperação internacional para a conservação dos recursos de altomar e a preocupação com a sua superexploração, tendo como objetivo promover a sustentabilidade desses. Estabeleceu-se diretrizes para a pesca, dentro dos limites estabelecidos pelos demais tratados e pelos direitos dos Estados costeiros (ONU, 1958, apud LEÃO et al., s/d, p. 13). À época, a baleação era uma importante indústria para diversos países, que capturavam grandes cotas de baleia. O rápido declínio da população de baleias que ocorreu no decorrer da década de 1960, evidenciado pelo fato de que a baleação não atingia mais as metas determinadas, fez com que até mesmo a indústria reconhecesse a seriedade do problema (LEÃO et al., s/d, p. 6).

Em 1982, a Comissão Baleeira Internacional (IWC) implantou uma moratória temporária à caça comercial com duração de quatro anos, a ter início em 1986, fixando a quantidade máxima de captura de baleias para fins comerciais em qualquer estação em zero, a fim de desenvolver um Procedimento de Gerência Revisado (RMP), que substituiria o Novo Procedimento de Gerência na função de determinar uma taxa sustentável de pesca de baleias para guiar a produção de novas cotas anuais produzidas pela IWC (OBERTHÜR, 1998, apud LEÃO et al., s/d, p. 6). Ao invés de produzir novas cotas e desfazer a moratória em 1990 como acordado, a IWC prorrogou a moratória durante outro ano, estendendo-a por tempo indefinido em 1992.

Apesar dos inúmeros pedidos de diversos países - com destaque para a Islândia, Noruega e para o Japão - visando à implementação da RMP, não foram feitos esforços concretos nesse sentido, principalmente devido à grande dificuldade enfrentada pela IWC em decidir o melhor mecanismo para o monitoramento, de modo a garantir que os limites fossem respeitados (OBERTHÜR, 1998, apud LEÃO et al., s/d, p. 7).

Em 1994, a IWC proibiu a caça comercial de baleias, independentemente do fim, na região definida como Santuário da Baleia dos Mares do Sul na Antártica, delimitando suas coordenadas e proibindo toda a atividade baleeira nessa região pelo período de 50 anos (IWC, 2012; OBERTHÜR, 1998, apud LEÃO et al., s/d, p. 11). Atualmente existem três santuários: no Oceano Índico, na Antártica e no México, assim como propostas para que outros também sejam criados, especialmente no Pacífico e no Atlântico. Em 2008, durante a reunião da CIB, realizada em Santiago, no Chile, para promover a discussão de diversos temas comerciais relativos à proteção às baleias, a principal pauta estava relacionada à criação do Santuário do 
Atlântico Sul. Contudo, após uma semana de discussões não se efetivou a criação de tal santuário e a manutenção da moratória à caça comercial de baleias tampouco foi alcançada.

\subsection{Estrutura institucional do regime de proteção às baleias}

A estrutura institucional da ICRW encontra-se baseada na Comissão Baleeira Internacional (IWC), que teve seu primeiro encontro em 1949, no âmbito da qual foram criados quatro comitês sobre assuntos específicos (científico, técnico, financeiro e administrativo), treze subcomitês e alguns grupos de trabalho com o fim de discutir os principais temas da agenda atual. Desde então, ela se encontra ao menos uma vez por ano. Hoje fazem parte dela mais de 80 países, incluindo países baleeiros, países que já foram baleeiros, e até países que nunca caçaram baleias, mas que participam por ter voz ativa na conservação de baleias ou por apoiar interesses baleeiros (MORON, s/d, p. 2).

Suas funções atuais são, precipuamente, estimular, recomendar ou, se necessário, organizar estudos e investigações relacionados às baleias e sua caça, recopilar e analisar informações estatísticas referentes às atuais condições e tendências das populações de baleias e os efeitos das atividades pesqueiras sobre elas, assim como estudar, avaliar e difundir informações relativas aos métodos que viabilizam manter e incrementar as populações de baleias (ÁLVAREZ; ANDRADE, 2012, p. 8). Além disso, a IWC recopila relatórios sobre a caça e registros estatísticos e biológicos, coordena e financia investigações sobre estes cetáceos e publica material sobre o assunto, podendo, inclusive, adotar recomendações dirigidas a qualquer governo contratante sobre qualquer assunto relacionado às baleias ou à sua caça, atendendo aos objetivos e finalidades da Convenção (ÁLVAREZ; ANDRADE, 2012, p. 8). Cumpre ressaltar que a IWC não conta com competência para aplicar sanções nos casos em que se efetuem violações à Convenção, motivo pelo qual deveria contar com mecanismos de controle mais rígidos que obrigassem os Estados a cumprirem as disposições da Convenção e seus documentos anexos.

\subsection{Debate quanto à atividade baleeira na atualidade}

$\mathrm{Na}$ atualidade, o extermínio das baleias é massivo na região norte e sul do globo, principalmente por atividades patrocinadas pelo Japão, Noruega e Islândia, países que abertamente praticam ou permitem a caça de baleias. 
Leciona Alexandra Leão et al. que o Japão adotou a moratória de imediato e suspendeu a caça de baleias para fins comerciais. No entanto, ao mesmo tempo, o país lançou o Programa Japonês de Pesquisa Baleeira sob Permissão Especial na Antártica (Japanese Whale Research Program under Special Permit in the Antarctic - JARPA). O referido programa teve sua primeira temporada de 1987 a 1998 e a última de 2005 a 2007, e sua principal atividade era capturar as baleias anãs na região do Santuário. Nessas expedições, o Japão matou 6.800 baleias anãs, comercializando sua carne no país (LEÃO et al., s/d, p. 23). A carne proveniente das mortes por motivos científicos pode ser comercializada, vez que o artigo VIII da ICRW permite que os subprodutos da pesquisa, no caso a carne de baleia, sejam processados e vendidos sob jurisdição governamental. No entanto, a caça com a única finalidade de comercializar a carne de baleia é ilegal pelas proposições da IWC.

O Japão pratica a baleação sob o pretexto de realizar pesquisas científicas, já que caça em águas internacionais, com a justificativa de que a utilização de métodos letais de coleta amostral visa reunir dados científicos suficientes para reestabelecer o uso sustentável dos recursos fornecidos pelas baleias, muito embora tais objetivos possam ser alcançados com a adoção de técnicas que não levem à morte do animal, como análise genética de pequenas amostras de pele, observações de fotos de alta qualidade, coleta de fezes, formação de um banco genético dos animais capturados para verificar as informações apresentadas pelos países baleeiros, identificação via satélite e dardos de biópsia. Métodos não-letais, além de serem mais adequados, ainda permitem repetidas observações do mesmo indivíduo, viabilizando, por exemplo, estudos comportamentais (MORON, s/d, p. 2).

Em resposta a pressão de alguns representantes políticos de outros países pela mudança na política baleeira do Japão, o Instituto Japonês de Pesquisa com Cetáceos afirma:

O fato de termos um ponto de vista diferente não significa que o Japão deve mudar
seu posicionamento. Os países não têm o direito de impor seus valores morais ou
éticos aos japoneses enquanto as baleias sejam utilizadas de maneira inteiramente
sustentável de acordo com leis e ciência internacional. O respeito mútuo pelas
diferenças, não coerção política, é a solução para esta difícil questão. O Japão
apresenta uma longa história de utilização sustentável de produtos de baleia para
alimentação. Tendo em vista o crescimento incerto dos suprimentos alimentares e seu
intercâmbio, a retomada do uso sustentável das baleias como abundantes recursos,
como uma das formas de adquirir proteína animal, é de importância vital futura, não
só para a população japonesa, mas para outros países com déficit de alimentos (apud
MORON, s/d, p. 7).

O Japão anunciou recentemente que vai voltar a caçar as baleias no Oceano Antártico com o propósito de coletar mais informações sobre a população de baleias-anãs da Antártica, caso a moratória não seja suspensa, e "estudar" o ecossistema marinho da região, decisão que 
tem sido recebida com indignação pelos grupos de conservação e representantes de outras nações.

O historiador Jeff Kingston, que mora em Tóquio, disse ao jornal The Japan Times que a volta da atividade baleeira desrespeita o Estado de Direito e terá repercussões negativas que superarão qualquer potencial para a indústria baleeira do país.

[...] para a imagem pública mundial do Japão, o retorno dessa atividade é uma proposta extremamente perdedora. É uma letra escarlate diplomática que influencia negativamente a opinião pública na Europa, América do Norte e Austrália ao longo de um programa que usa o dinheiro do contribuinte para matar algo que quase ninguém anseia. Tudo por causa de uma identidade nacional que poucos abraçam (apud Climatologia Geográfica, 2015).

A Noruega voltou a caçar baleias em 1993, e a Islândia, em 2002, dentro de seus limites costeiros, o que permite a baleação muito acima das cotas e recomendações da IWC e dificulta mais ainda alguma forma de regulamentação internacional, já que essa se destina a atividades em águas internacionais (MORON, s/d, p. 2). A pesca artesanal nativa também persiste, em cotas menores, em países como a Dinamarca (Groenlândia), Federação Russa (povoados indígenas Chukotka), São Vicente e Granadinas e Estados Unidos (Alasca), como meio de subsistência. A baleação ainda ocorre em países fora da jurisdição da IWC, como é o caso do Canadá.

A IWC argumenta que a conservação e o bem-estar animal são as principais razões para a prática da caça permanecer proibida, recomendando o turismo de observação como uma maneira mais apropriada e sustentável para usufruto das baleias (MORON, s/d, p. 3). Tal prática consiste em passeios realizados por barcos, pelo ar ou mesmo por terra, para observar, nadar com e ouvir algumas espécies do mamífero, em geral para fins recreativos. Esta indústria vem experimentando um dos maiores crescimentos no setor do mercado internacional de turismo, expandindo-se rapidamente a partir dos anos 1990 (CHEN; KUO; MCALEER, 2012, apud LEÃO et al., s/d, p. 18).

De fato, percebe-se que há mudanças no foco da discussão das atividades baleeiras, cujo produto - as próprias baleias - passa a ser encarado como um recurso natural que deve ser utilizado e gerenciado de forma diferenciada, por não se renovar facilmente (GAMBELL, 1993, LEÃO et al., s/d, p. 20). A mudança no debate pode ser atribuída, principalmente, aos apelos de uma sociedade civil cada vez mais consciente dos problemas ambientais e da necessidade de preservar as espécies ameaçadas de extinção.

Juliana Rodrigues Moron acrescenta o argumento de Joji Morishita, que defende em seu trabalho que o fator ético e cultural constitui um dos principais empecilhos para se chegar 
a um consenso internacional sobre a caça e proteção das baleias, havendo uma colisão existente entre as nações anti-baleação, que a visualizam como uma atividade focalizada nas baleias e consideram a preservação das populações naturais, com pesquisas predominantemente não letais e esforços para diminuir ameaças a elas que não a caça (como poluição e observação excessiva de baleias), e as pró-baleação, que a enxergam como uma atividade focalizada no ser humano, priorizando a preservação da cultura dos povos e a economia (MORISHITA, 2006, apud MORON, s/d, p. 7).

A humanidade tem de enfrentar o fato de que hoje a crise ambiental está sim diretamente ligada a questões éticas e políticas. Com o apogeu da ideologia do progresso, que chancela a exploração da natureza a fim de dela se extrair a matéria-prima para o desenvolvimento técnico e industrial, demorou o ser humano a despertar para os riscos e consequências desastrosas de suas atividades, em especial a atividade baleeira. Outro fato que não pode mais ser ignorado é o de que os recursos finitos do planeta não se renovarão na mesma velocidade de sua exploração, se os níveis de consumo continuarem tendo como referência os padrões ocidentais (NIGRO, 2014).

Assim, novas responsabilidades surgem à medida que se fortalece a consciência de que o mundo em que se habita é uma realidade viva com a qual se deve relacionar harmoniosamente, posicionamento que ecoa a mensagem ambiental da obra Moby Dick.

De qualquer modo, além da caça predatória, o risco de extermínio de algumas espécies se agrava em razão da diminuição do krill que lhes serve como alimento, e pelo fato do ciclo de reprodução da maioria das espécies ser lento, pois uma fêmea tem apenas um filhote a cada três anos. A esta realidade soma-se uma série de questões relacionadas com os problemas dos oceanos que afetam as baleias e o meio que elas habitam, como o aumento da temperatura das águas, responsável pela elevação do nível dos mares, a alteração das correntes oceânicas e o crescente tráfego das embarcações. Destacam-se, ademais, as colisões das grandes baleias com embarcações, as capturas acidentais em redes de pesca e o fato de que os oceanos são cada vez mais ruidosos, o que desorienta estes cetáceos, dificultando que se comuniquem entre si, evitem predadores, cuidem de suas crias, reproduzam-se e consigam seguir as rotas migratórias tradicionais. 


\section{O CASO AUSTRÁlia VS. JAPÃO PERANTE A CORTE INTERNACIONAL DE JUSTIÇA}

O Programa Japonês de Pesquisa Baleeira sob Autorização Especial na Antártida (JARPA), que está em sua segunda fase, teve seu início entre 2005-2006 com estudos de viabilidade por dois anos, sendo seu início efetivo em 2007-2008. O foco da segunda fase do programa era incluir as espécies da região do Santuário como objeto de pesquisa. Esse programa resultou em um número muito alto de mortes das mais diversas espécies de baleias, como, por exemplo, as baleias minke, consideradas de alto risco de extinção (LEÃO et al., s/d, p. 23).

A IWC recomendou diversas vezes ao Japão reavaliar o programa, as suas técnicas e seus objetivos, tendo em vista que o programa JARPA II estaria ameaçando o meio-ambiente e as populações de baleias. O Japão, entretanto, não seguiu nenhuma recomendação (LEÃO et al., s/d, p. 23).

Em 31 de maio de 2010, a Austrália depositou junto à CIJ uma requête contra o Japão referente à violação da Convenção Internacional para Regulamentação da Pesca da Baleia (1946) e outras obrigações internacionais relativas à preservação dos mamíferos marinhos e do meio ambiente no Santuário do Oceano Antártico. A Austrália questionou se as permissões concedidas, pelo Japão, no âmbito do JARPA II, para a pesca de baleias com fins de pesquisa científica, cumpririam de fato os requisitos do artigo VIII, parágrafo 1, da Convenção, diante do volume de baleias capturadas e das ínfimas descobertas científicas alcançadas (OLIVEIRA; MARINHO, 2014, p. 16).

O governo australiano salientou que o Japão deveria observar o limite zero em relação à matança do mamífero em questão bem como tinha por obrigação se abster da caça de baleias para fins comerciais no Santuário do Oceano Antártico, defendendo que todos os prejuízos ambientais referentes às atividades baleeiras praticadas pelo Japão não poderiam ser justificados e permitidos por meio do artigo VIII da ICRW. Assim, tendo em vista todos os motivos supracitados, o governo da Austrália solicitou à Corte que ordenasse ao Japão a suspensão do JARPA II até que o programa estivesse de acordo com as obrigações internacionais e a revogação de todas as permissões, autorizações e licenças concedidas para programas de pesquisa científica sobre as baleias da Antártica (OLIVEIRA; MARINHO, 2014, p. 16). 
O Japão, em sua defesa, alegou que as suas atividades são lícitas e que as permissões concedidas atendem aos requisitos do artigo VIII, questionando a competência da Corte para decidir sobre o caso (OLIVEIRA; MARINHO, 2014, p. 16). Esse caso, no seu início, envolvia apenas o Japão e a Austrália, mas a Nova Zelândia, que também integra a IWC, no dia 22 de dezembro de 2012 apresentou um pedido para intervir perante a Corte, baseando-se no artigo 63 do Estatuto da CIJ.

A Corte entendeu que o caso versava sobre a questão de saber se as atividades autorizadas pelo Japão, no JARPA II, eram ou não compatíveis com as obrigações assumidas no âmbito da Convenção Internacional, e não se as atividades se desenvolviam em zona marítima australiana e por isso eram proibidas. Logo, a Corte excluiu a exceção de incompetência solicitada pelo Japão (OLIVEIRA; MARINHO, 2014, p. 16).

A CIJ fez questão de esclarecer que o JARPA II poderia ser considerado um programa de pesquisa científica por duas razões: o programa descrevia os objetos de estudo de maneira correspondente aos quatro objetivos a que se propunha, e haveria coleta e análise sistemática dos dados por cientistas. Mas as provas indicaram que o programa JARPA II não apresentava condições razoáveis para se atingir os objetivos pretendidos. Afinal, o período de captura seria insuficiente para alcançar "resultados estatisticamente relevantes". Quanto aos resultados científicos do programa, a avaliação da Corte foi de que estes foram modestos, diante do limitado número de produções científicas publicadas pelo Japão em virtude do programa (OLIVEIRA; MARINHO, 2014, p. 19).

A Corte considerou insuficientes para justificarem a matança de mais de três mil baleias as três apresentações em simpósios científicos, oito artigos apresentados ao Comitê Científico, dos quais seis deles são apenas relatórios de cruzeiro do JARPA II; outro se refere a um estudo de viabilidade do programa; e o último diz respeito à identificação com utilização de fotos de baleias azuis (OLIVEIRA; FONSECA, s/d, p. 12).

Para a Corte, faltou transparência no JARPA II no que se referia à escolha do tamanho das amostras em diferentes parâmetros do estudo. A caça quase que exclusiva a baleias minke pôs em dúvida os propósitos científicos do projeto fornecidos pelo próprio Japão. Se a finalidade era examinar o ecossistema e a concorrência entre as espécies de baleias, não se justificaria a coleta quase que exclusiva de apenas uma espécie. Quanto ao calendário da pesquisa, a Corte estimou que o Japão poderia ter oferecido uma previsão de metas intermediárias ao longo da pesquisa mesmo que este não houvesse definido a duração do programa (OLIVEIRA; MARINHO, 2014, p. 19). 
Além disso, pesou contra o Japão o fato de estarem disponíveis técnicas não letais para se atingir alguns dos objetivos do programa, as quais não foram consideradas como opção no momento da concepção do JARPA II (OLIVEIRA; MARINHO, 2014, p. 19). Outro fato negativo à argumentação japonesa foi o uso acentuado de métodos letais na condução do programa e o significativo impacto ambiental causado pelo aumento no número de baleias mortas, o que demonstrou a não observância japonesa em relação às resoluções e diretrizes da Comissão Baleeira Internacional. A CIJ considerou inexplicável e inadmissível a diferença significativa entre o número de amostras alvo do JARPA II e o número real de baleias que foram mortas quando o Programa estava em ação (OLIVEIRA; FONSECA, s/d, p. 11).

Por fim a Corte constatou a falta de cooperação do projeto JARPA II com outras instituições da mesma área de pesquisa japonesas e estrangeiras. Pelos motivos listados acima, a Corte, por doze votos a quatro, decidiu que a permissão especial concedida ao programa JARPA II não tinha por finalidade a pesquisa científica (e sim a prática da caça comercial de baleias) e violava os termos da Convenção Internacional para a regulamentação da Pesca de Baleia e que, portanto, deveria ser revogada (OLIVEIRA; MARINHO, 2014, p. 20).

A Corte Internacional de Justiça caminhou bem ao decidir pela revogação da permissão especial concedida pelo Japão ao JARPA II. Contudo, a decisão não se pautou nos princípios do Direito Internacional Ambiental, tais como o patrimônio comum da humanidade, a equidade intergeracional e a precaução, muito embora seja incontestável que atividades como a caça predatória de baleias representa um retrocesso evidente às conquistas no que tange à proteção ambiental (OLIVEIRA; FONSECA, s/d, p. 22).

\section{CONSIDERAÇÕES FINAIS}

Não é curioso que um ser tão imenso quanto a baleia veja o mundo com um olho tão pequeno, e escute o trovão com um ouvido menor do que o de uma lebre? Mas se seus olhos fossem tão grandes quanto as lentes do grande telescópio de Herschel; e seus ouvidos tão amplos quanto os pórticos das catedrais; teria por isso um alcance maior da visão ou ficaria com o ouvido mais apurado? De modo algum. Por que, então, você procura "ampliar" sua mente? Aprimore-a.

Os oceanos cobrem duas terças partes da superfície do planeta e a atenção da comunidade internacional é crescentemente direcionada à preservação da vida marinha por meio de diversos mecanismos de cooperação internacional. Em relação às baleias, problemas como a caça indiscriminada, a contaminação, a poluição sonora, a exploração de 
hidrocarburetos, colisões com embarcações e mudanças climáticas dificultam claramente a sua proteção.

No início do século XIX, a atividade baleeira era muito pequena devido à baixa quantidade de recursos tecnológicos e estudos relacionados a ela. No entanto, com o avanço tecnológico dos navios e dos instrumentos de caça, ela passou a ser realizada com mais frequência e de forma predatória, por povos que almejam não apenas sua subsistência, mas também (e principalmente) a obtenção de lucros.

Reconhecendo a necessidade de manejar a situação, evitando assim que a baleação provocasse a extinção das populações de baleias e gerasse uma alteração no ecossistema global, a comunidade internacional firmou alguns acordos internacionais, tendo em vista que a maior parte das populações de baleias se encontram em águas internacionais.

Neste cenário, a Comissão Baleeira Internacional, criada no seio da Convenção Internacional para a Regulamentação da Pesca da Baleia, revela-se como o organismo competente para garantir a conservação apropriada das populações baleeiras e incentivar a caça sustentável das espécies que não se encontram ameaçadas. Para tanto, a Comissão estabelece regulações como quotas de caça permitidas, moratórias, métodos de captura e áreas protegidas - como os santuários - quando as medidas são aprovadas por três quartos dos Estados-membros que a compõem. Contudo, dentre os Estados signatários da Convenção, países como o Japão, a Noruega e a Islândia descumprem as medidas protecionistas e incentivam uma posição de impasse que limita parcialmente a eficácia do regime.

Vale ressaltar que existe um valioso potencial econômico que reside na própria preservação das baleias e que pode ser lucrativamente explorado. Assim, devem ser incentivadas mudanças culturais destinadas a valorizar a prática do ecoturismo, como a observação de baleias (whalewatching), que é um mercado em crescimento em diversos lugares do planeta.

Da mesma forma, é importante insistir na aplicação de medidas como um maior intercâmbio técnico-científico e de gestão entre os Estados, conjugadas com o incentivo ao cumprimento das já existentes normas de cunho ambiental internacional. Para tanto, exige-se uma gestão eminentemente disciplinar a ser incentivada mediante a atuação de instituições nacionais e internacionais de diversas naturezas em cooperação com as comunidades locais e a sociedade civil.

A Corte Internacional de Justiça, na decisão do caso 'Austrália vs. Japão’, não apenas se declarou competente para o exame do projeto, como definiu critérios para a determinação do 
caráter científico do programa que poderão servir de base para outras decisões que envolvam o uso de pesquisa científica. A decisão limitou o poder discricionário dos Estados na concessão de licenças e permissões para a caça, captura e processamento de baleias, ao tornar tal decisão passível de controle pela CIJ.

Cabe destacar que Herman Melville foi não só um escritor autêntico, como também um "profeta" ecológico à frente de seu tempo, anunciando já na década de 1850 o que aconteceria com a natureza e a humanidade se o homem não revertesse sua atitude para com a natureza. Lendo nas entrelinhas de Moby Dick, verifica-se que ele concebeu o homem como parte da natureza, reconhecendo o seu valor intrínseco e, acima de tudo, a condenação daquele por explorá-la. Ao mostrar a ávida busca de Ahab, consumido por seu incontrolável desejo de vingança e dominação sobre a natureza, Melville mostra claramente que tal ambição só resultaria em desastres e danos irreparáveis à natureza, bem como na morte do homem. A sobrevivência de Ishmael, ao contrário, transmite os pontos de vista ecológicos do autor. Através dele, Melville afirma que o homem deve reconhecer o seu lugar na Terra e aprender a viver em "termos amigáveis" com todos os demais seres que aqui habitam.

Melville condenou e criticou os rumos da industrialização e do desenvolvimento econômico nos EUA e no mundo, tendo-se desiludido com o materialismo servil, a super exploração de recursos naturais, a falta de integridade entre os semelhantes e o modo de vida despojado de significado espiritual que caracterizou o Novo Mundo em meados do século XIX. Nota-se que ele se esforçou em sugerir um novo tipo de civilização, uma que iria priorizar uma relação harmoniosa entre o homem e a natureza e o consequente crescimento espiritual do homem.

As palavras de Melville ressoam os apelos do ambientalismo dos dias atuais, pois a obra ensina a leitores modernos uma lição que jamais se imaginou: que os seres humanos e a natureza devem coexistir harmoniosamente. E para alcançar tal objetivo, o homem deve levar uma vida pautada pelos princípios ambientais, em vez de perseguir uma satisfação material inatingível. 


\section{REFERÊNCIAS}

ÁlVAREZ, Ana Muñiz; ANDRADE, Mayra Thais Silva. Os desafios da aplicação dos direitos fundamentais ambientais sob a ótica de proteção à vida marinha baleeira. Cadernos de Direito, Piracicaba, v. 12, p. 149-163, jul.-dez. 2012. Disponível em: https://www.metodista.br/revistas/revistas-unimep/index.php/cd/article/.../1044. Acesso em: 24 set. 2016.

Climatologia geográfica. Japão anunciou que voltará a matar baleias mesmo com a proibição. Disponível em: http://climatologiageografica.com.br/japao-anunciou-que-voltaraa-matar-baleias-mesmo-com-a-proibicao/\#ixzz4LIDElikj. Acesso em: 25 set. 2016.

Comissão Baleeira Internacional (International Whaling Comission). Convenção Internacional para a Regulamentação da Caça à Baleia e Protocolo. Disponível em: http://www.iwcoffice.org/. Acesso em: 07 ago. 2016.

Comissão do Atlântico Norte para os Mamíferos Marinhos (NAMMCO). Disponível em: http://www.nammco.no/. Acesso em: 22 ago. 2016.

Convenção de Bonn sobre Espécies Migratórias (CMS). Disponível em: http://www.cms.int/. Acesso em: 30 ago. 2016.

Convenção sobre Diversidade Biológica (CDB). Disponível em: http://www.cbd.int/convention/parties/list/. Acesso em: 18 ago. 2016.

DUARTE, Cyro. O protagonismo das baleias na questão ambiental. Disponível em: http://amazonforever.org/site/pt/o-protagonismo-das-baleias-na-questao-ambiental/. Acesso em: 24 set. 2016.

Enciclopédia

<http://escola.britannica.com.br/article/574445/cachalote>. Acesso em: 25 set. 2016.

FERRAZ, Heitor. Herman Melville e Moby Dick: vida e obra. In: MELVILLE, Herman. Moby Dick. Tradução Berenice Xavier. São Paulo: Abril: 2010. Clássicos Abril Coleções, v. 15. p. $415-428$.

Instituto Internacional de Desenvolvimento Sustentável (International Institute for Sustainable Development). Disponível em: http://www.iisd.org/. Acesso em: 30 ago. 2016.

Instituto Sea Shepherd. Disponível em: http://www.seasheperd.org/. Acesso em: 30 ago. 2016.

LEÃO, Alexandra; SOARES, Joana Lacerda; MELO, Luísa Barros de; MONTEIRO, Rafael. Atividade baleeira e o caso "Austrália v. Japão" - análise histórica da tensão entre preservação e exploração das espécies. Disponível em: http://sinus.org.br/2014/wpcontent/uploads/2013/11/CIJ.pdf. Acesso em: 24 set. 2016.

MELVILlE, Herman. Moby Dick. Trad. Vera Silvia Camargo Guarnieri. São Paulo: Landmark, 2012. 
MORON, Juliana Rodrigues. O direito internacional da preservação das baleias. Disponível

em: http://www.abolicionismoanimal.org.br/artigos/odireitointernacionaldapreserva_odasbaleias.p df. Acesso em: 24 set. 2016.

NIGRO, Rachel. Desafios éticos da sustentabilidade. Disponível em: http://era.org.br/2014/06/desafios-eticos-da-sustentabilidade/. Acesso em: 26 set. 2016.

OLIVEIRA, Camila Martins de Oliveira; FONSECA, Elisa Resende Bueno da. A Corte Internacional de Justiça e o meio ambiente: uma análise do caso pesca de baleia na antártica sob a luz do direito internacional para a humanidade no século XXI. Disponível em: www.publicacoesacademicas.uniceub.br/index.php/rdi/article/download/3204/pdf. Acesso em: 25 set. 2016

OLIVEIRA, Liziane Paixão Silva; MARINHO, Maria Edelvacy. O caso Austrália c. Japão perante a Corte Internacional de Justiça.

Organização Marítima Internacional (OMI). Disponível em: http://imo.org/. Acesso em: 30 ago. 2016.

SANTOS, William Carlos Dantas dos. O arpão obsessivo: Moby Dick e a vingança de Ahab. Guarabira: UEPB, 2011. 23f. Disponível em: http://dspace.bc.uepb.edu.br/jspui/bitstream/123456789/1481/1/PDF\%20-

\%20William\%20Carlos\%20Dantas\%20dos\%20Santos.pdf. Acesso em: 24 set. 2016.

SOUSA, Maria Isabel de. As questões ecológicas em Moby Dick, de Melville, e Walden, de Thoreau. Disponível em: https://ria.ua.pt/bitstream/10773/11440/1/7817.pdf. Acesso em: 24 set. 2016. 